\title{
TranSFORMATION OF EMPLOYABILITY SKILLS THROUGH CO-OP EXPERIENCES
}

\author{
Haaniyah Ali and Dr. Jeffrey Harris \\ Lassonde School of Engineering, York University \\ ha97@yorku.ca, jpharris@yorku.ca
}

\begin{abstract}
The structure of co-operative programs gives students the opportunity to transform employability skills. Using a proposed conceptual framework and inspiration from Mezirow's Transformative Learning Theory, this paper analyzes four engineering students in varying disciplines across the three contexts that a co-op experience provides: pre co-op school setting, co-op work placement and the post co-op school setting. Using reflection and by adapting to their settings, these students transformed their communication, organization/ time management and initiative/ responsibility skills. Analyzing these skills and experiences against the framework, we can see how the details and specifics of the transformation varies for each student; however, each student needs to experience each stage for successful transformation. Each of the stages then feeds into and helps further the skills as it changes.
\end{abstract}

Keywords: co-operative education, skill transformation, work-integrated learning, transformative learning theory, general skills, engineering

\section{INTRODUCTION}

Co-op education has become an integral part of many engineering programs and rather common, even vital, to the engineering curriculum as a whole. Co-op programs vary in their structure and duration, however the concept of "work-integrated learning" is translating across many schools. These programs aim to give industry experience to compliment a student's academic journey. As described by Co-operative Education and Work-Integrated Learning (CEWIL) Canada, co-op programs are created to provide benefit to students, employers and learning institutes alike by fostering skills, new ideas and relationships across the traditional working boundaries [1] They also exist to provide opportunities to explore and grow employability skills - skills that are transferable and help one in the professional realm.

As these programs have progressed, Van Gyn describes how there has been a lot of work done to understand the impact of co-op on industry/ career [2]; on the other hand, work can be done to further understand how these experiences impact and transform a student's learning.

In particular, there seems to be little research into understanding how academic settings and co-op experiences work together to develop these skills. The focus of this study is to explore not only skill development, but to investigate how these skills are both transformed and transformative by being applied in these varying contexts. Transformative learning theory (TLT) is useful for when learners encounter problems that cannot be resolved by their past learning methods; instead, learners must then redefine the problem and the process by which they will now address the problem [3]. This means that practises cannot be replicated, or completely reimagined in new settings - they must be re-evaluated, and new meanings and practises must constantly be created. Through reflection and analysis, learners can build on their previous learning to find nuanced ways to transform skills.

\subsection{Background Literature}

This is a continuation of our work published in CEEA/ACEG 2019 [4]. In that work, we focused on the transition between co-op and school contexts and which skills transferred successfully. Our results found that these skills did transfer, however there was a lot of variation in how they transformed. This transformation allowed these skills to go across contexts. This paper explores the nature of the transformation in greater detail, with data from a larger group of participants.

The benefits of co-op programs have been explored quite deeply by various other authors; some focus on the impact it has on GPA [5], [6], [7] and [8], general skill development and innovation [9], [10] and [11] and 
student well-being [12]. These papers all outline how skills are developed through co-op experiences and make a great case for the lasting impact that co-op programs have on student learning and career readiness. Our paper aims to take that thinking forward by analysing which skills and experiences allow these benefits to prevail and how skills are not just developed but transformed.

In prior research, we highlighted the impact of skill preparation before co-op on the ease of adapting in a new work environment [13]. We found that there was a discrepancy between students in different engineering discipline in how developed their employability skills were. This work emphasized the impact of the initial school context on skill development; yet that work does not look at the process of transformation across settings and in relation to the skills.

McRae identified which conditions optimize and support transformative learning in WIL [14]. Some conditions that encourage a transformative experience are: knotworking and co-configuration of policies with supervisors; and supportive networks (both professional and personal) that allow students to have a transformative experience. McRae focuses on how to make the workplace experience transformative, as a whole. She does not pull focus into how these environments encourage skill transformation specifically but implies that skills would be developed through such experiences. Furthermore, Buchs outlines how social skills develop over a co-op program and how school can prepare students to succeed in a workplace setting [15]. They highlight the important roles collaboration and overcoming competition can play and some intervention techniques that can be implemented to do so. They do not pull much focus on skill transformation, but rather skill development in a co-op setting. Reilly and Teslenko, on the other hand, highlight how co-op helps students transition from school to their first career and how the co-op model has aspects of transformative learning [16]. In their work, they highlight how transformative learning calls for "critical reflection, dialogue and holistic learning". Leveraging those points, they used TLT to understand how co-op can impact a student's understanding of graduate attributes. Our work focuses on skill development specifically, whereas Reilly and Teslenko take the graduate attribute lens for understanding and skill transformation.

In all of these studies, a gap exists: how past experiences can be examined to understand the transformation of skills that happens through co-op. In particular, how the changing environments (from school, to work and back) play their roles.

1.1.1 Research Question. This paper is centered around a research question that aims to understand and fill that gap: "How can we track and analyse the transformation of skills across changing learning environments, such as those occurring as a result of a co-op program?"

\subsection{Methodology}

A phenomenological methodology was used for this research. We chose this qualitative approach because we wanted to pull focus on the subtle details of the lived experiences of each of these students. Qualitative research a deeper understanding of contextualized experiences, allowing the researcher to uncover nuances that can be overlooked in quantitative research. Our phenomenological approach is grounded in the interpretive research paradigm with the ontology that a student's learning experience is inherently context dependent. Therefore, this research seeks to understand these individual experiences, giving students a place to articulate each of the factors that went into their experiences; it also allowed students to naturally offer perspectives where they saw fit. The goal was not primarily to facilitate reflection, but reflection was explored where it naturally occurred.

\subsection{Framework}

The analysis of each skill follows how the skill is initially introduced and then developed across the contexts. Figure 1 below shows the conceptual framework that will be followed, and participant accounts will showcase the different practises that encompass various skills.

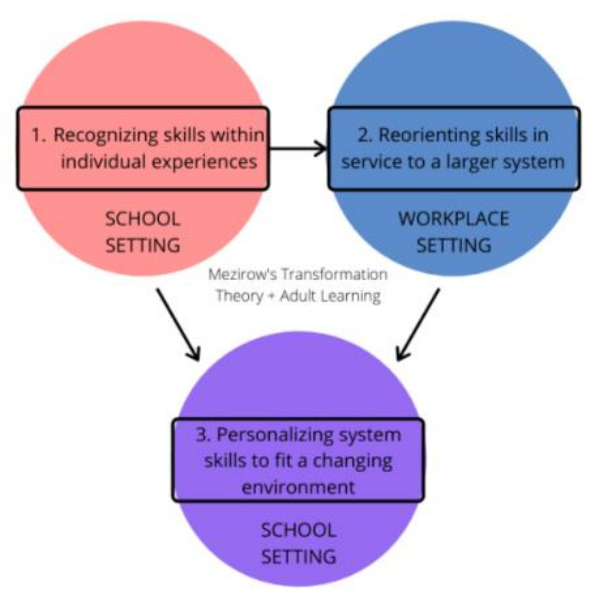

Fig. 1. Conceptual Framework.

In this study we are looking at 3 settings: the school setting (pre co-op), workplace setting (during co-op) and returning to the school setting (post co-op). Successful and lasting transformed skills follow 3 simple steps, that each lead into a future setting:

i. an initial recognition of skills for personal success and use 
ii. a reorientation of skills to serve a larger system (i.e. the company or industry where they did their co-op program)

iii. personalizing the skill that was initially recognized and then reoriented, to fit any changing environment.

This framework is centered around transformative learning theory (TLT), as described by Mezirow's model from 1978. At its core, transformative learning encourages the reflection of past experiences and using those experiences to build new meaning and learning [3]. This model is specifically used to understand adult-learning. We can follow certain skills through this framework, and thereby, through a transformative process. We can also track skills that do not follow this process and how transformative (or lack thereof) they have been. It is important to note that, because TLT is founded on critical reflection, no two participants will have the exact same skill transformation because critical reflection is a personal experience. Furthermore, this framework is used as a guide to understand transformation and should not be seen as a to-do to incite or enforce transformation. Further work would have to be done to make such claims.

\subsection{Data Collection and Analysis}

Qualitative, interview-based data were collected for this research project. We interviewed 6 students to understand their skills. A total of 12 interviews were done, 2 per participant. The initial interview was done during a student's co-op term and the second interview occurred when they returned for their school term. The length of the co-op term, the engineering program and year of study varies across students. Table 1 summarizes the details of the participants. The names of the students have been replaced to protect their privacy and allow for easier referencing.

Table 1: Summary of Participants. (Strikethrough indicates that the participant was excluded from data analysis)

\begin{tabular}{|l|l|l|l|}
\hline & $\begin{array}{l}\text { Pseudo } \\
\text { nym }\end{array}$ & Program & $\begin{array}{l}\text { Co-op } \\
\text { Duration }\end{array}$ \\
\hline Student 1 & Kevin & $\begin{array}{l}\text { Aechanical } \\
\text { Engineering }\end{array}$ & 4 months \\
\hline Student 2 & Faylor & $\begin{array}{l}\text { Mechanical } \\
\text { Engineering }\end{array}$ & 4 months \\
\hline Student 3 & Jonah & $\begin{array}{l}\text { Mechanical } \\
\text { Engineering }\end{array}$ & 4 months \\
\hline Student 4 & Lila & Civil Engineering & 4 months \\
\hline Student 5 & Noelle & Software Engineering & 4 months \\
\hline Student 6 & Idris & $\begin{array}{l}\text { Computer } \\
\text { Engineering }\end{array}$ & $\begin{array}{l}16 \\
\text { months }\end{array}$ \\
\hline
\end{tabular}

CEEA-ACEG21; Paper 127

University of Prince Edward Island; June 21 -23, 2021
Themes and reflections were extracted from transcriptions of the interviews in the analysis phase, to group and better understand these experiences. Students' experiences of skill transformation were grouped into three different themes based on the type of skill. In the analysis, each of these are represented in the form of multiple narratives, in order to reveal the diverse ways in which students can experience skill transformation.

\section{RESULTS AND DISCUSSION}

The 6 participants each shared their own experiences and co-op stories. The following skills emerged as the most commonly discussed across students: communication, organization/ time management and initiative/ responsibility. However, not all students exhibited each of the skills listed. This reiterates the assumption stated in the framework: skill transformation is a personal, unique experience. We will be analyzing the skills listed above, through the experiences and words of the participants. Table 2 summarizes which participants highlighted the transformation of each skill. The most transformative and thematically relevant skills for each participant is highlighted in the following analysis.

Table 2: Participant to Skill Analysis Summary

\begin{tabular}{|l|l|}
\hline Skill & Participants \\
\hline Communication & Lila, Noelle, Jonah \\
\hline Organization & Jonah, Lila \\
\hline Initiative/ Responsibility & Noelle, Idris \\
\hline
\end{tabular}

It is important to note that students 1 and 2, Kevin and Taylor, will be excused from the analysis because of the nature of the questions they were posed during their interviews. Those interviews were conducted during an earlier stage of this research [3], and the data does not give a clear enough picture of the pre co-op school setting, making it challenging to analyse those students' experiences through the conceptual framework.

Also, in accordance with the framework seen in fig. 1, the results are structured in the following way: school experiences before the co-op placement; work experience during the co-op placement; finally, school experiences after returning from the co-op placement. The analysis is done as the results are presented.

\section{1a Communication: Lila}

Communication is a skill that was discussed by nearly every participant. All four participants discussed how useful communication was, both in school and in the workplace. For this analysis we have outlined the experiences of three of the students. This is because their 
experiences show nuances that were most different. According to each student, communication was present in everyday interactions, as well as in the classroom.

As Lila mentioned regarding her pre co-op school experiences, "general skills are harder for engineers... which is why we take courses like [communication course] and [project management course]." She also mentions how the project management course was "nice to an extent" because it gave an introduction to technical and communication tools that she had not interacted with previously. However, Lila did make a case for these courses being more beneficial for students who may have less experience with communication. This was a sentiment that was prevalent across each student, best articulated here. This course acted as simple introductions to communication in an engineering setting. For Lila, communication was a skill she was already practising, but this professionalism lens was helpful.

In her co-op setting, Lila expanded her communication skills from sharing and expressing ideas to include "personal connections" and "processing what [people] want". Communication was used as a tool for problem solving and understanding the needs of her superiors and clients alike. Furthermore, Lila picked up on "hidden communication" that occurred in her workplace. As she described it, being able to pick up on behaviours that were appreciated and annoyed in the workspace and adjust accordingly aided in a smooth working environment. There are clear parallels that can be drawn to the communication Lila had done before. Lila specifically mentioned how the communication course helped articulate with professionalism. This was something she could bring into the co-op placement via individual and group interactions, as well as through report writing. Furthermore, Lila enforced the connection between extracurriculars and better communication, in "delegating tasks" and "understanding what people are communicating to you". When reporting on her experiences in co-op, she specifically highlighted the value of her leadership skills because they helped her understand the expectations of her superiors and what they were saying. These contextspecific skills became larger and more sophisticated for industry use.

When returning to school, Lila made a specific comment regarding her interactions with other students. She was told by many classmates and fellow club members that she was more "professional" in how she handled herself and the improved quality of her emails; what stuck out was her lack of awareness for these things. She did not report them as explicit but more so something that happened naturally and according to her settings. Similarly, when she returned to school, so picked up on the casual nature of some of her interactions on campus. She reported being at school as little as possible because she would get "drag[ged] into things that [she] doesn't like anymore".
Much like the non-verbal communication in the office, Lila realized that there were certain behaviours and communication styles that were not effective. And when faced with them, she altered her behaviour to better suit her needs. This use of communication as a tool for problem solving and the second-nature of this skill shows transformation. The skill no longer lives in a bubble of professionalism, but as something she utilizes in her overall interactions.

\section{1b Communication: Noelle}

Similarly, Noelle mentioned the communication course and how it was a "pretty important" part of her education. She went on to discuss how this skill was used in her club involvement, from writing official documents to working with others. Noelle commented on the importance that communication must have "in University, even industry, like everywhere". It is important to note that she was already working when she made this comment, but the comment was made in reference to her school experiences. This highlights Noelle's mindset and the level of transformation her communication skill had already achieved. And this mindset facilitated internal reflection towards adaptability.

During co-op, Noelle found communication skills vital for teamwork and professional correspondences. Despite having many experiences with clubs and teamwork, Noelle found it hard to work with some colleagues when ideas would clash. She had to learn to "get [her] point across without showing them that you're fighting with them or you have a strong different opinion". This balanced communication where that maintains professionalism but also values her own opinion enough to fight to share it, was something she had to learn. She also mentioned having to "stop thinking like a developer and think like a person" when communicating changing and processes to other teams. This need to balance technical knowledge with general jargon was a new facet of the skill that she had not yet explored. She had previous experiences with clubs and technical writing but in the co-op setting this was transformed to include higher stake situations. It was not just for her benefit to enjoyment - she adapted to do a better job.

Upon returning to school, Noelle framed her communication practises as "professionalism". Using new techniques from co-op, Noelle found that writing emails and dealing with people in her learning environment was becoming second nature. Communication was no longer something that would be necessary in any setting - it just happened in all of these changing contexts. She found herself being more comfortable in any context she faced: as she put it, "it's not about who I'm presenting to, it's just the skills". This quote highlights an interesting shift that happened for Noelle: she was no longer limited to certain 
experiences for her communication to flourish. In her initial interview, she limited her communication practises to clubs and in her dealings with other students (although recognized the transient nature of the skill); in her co-op she broadened this boundary a little more, focusing on how communication helped her complete her weekly tasks and within her various interactions. And yet, when she returned to school, opportunities to communicate were everywhere.

\section{1c Communication: Idris}

According to Idris, his "communication - prior to co-op and after co-op - went through the biggest transformation" and how it had "become a more holistic thing". This was a realization he came to after returning to school.

Prior to co-op, Idris mentioned the benefit that communication courses had on his understanding of professionalism. For him, the emphasis of "respectful twoway communication" when working with code was key. The courses well-articulated the value of that facet of communication and this was what he took into the co-op placement.

In co-op, that level of "respect and patience" really helped him when dealing with the clients (who were security administrators from external companies he aided in IT support). He also spoke about how he would have to "ease the tension in order to bring that level of respect back into the conversation". This was not a specific drill he had done in his courses; however, he used his personal and decontextualized knowledge from school to then perform better at work. This general air of enforced professionalism and respect in interactions were what he gained from his co-op experience and was able to bring into school.

When returning to school, Idris felt the impact of the full transformation. He found that the aspect of personability he had learned in co-op when interacting with other professionals helped him, not only to "de-escalate" situations with club members and project teammates in school, but also in his life. He mentioned a sense of grown confidence in putting himself out there and communicating his perspective. This move towards general growth for himself used all three of his experiences and very much transformed communication into something that he could and wanted to for personal use.

\section{2a Organization/ Time Management: Jonah}

Organization was a theme in many interviews. For some students this came out in time management and others it was task management. As a whole, students also reported the transformation as an increase in time value when it came to making decisions about what to do and comparing priorities.
For both students in this analysis, what began as time management very much translated to the value that they gave to time, and its use as a decision-making tool. Through the transformation of time management, students began re-evaluating the work they put effort into and how they oriented their priorities.

Before co-op, Jonah mentioned how time management was vital for success in school. In particular, he highlighted its importance because he recognized that he was not great at it and would fall into the cycle of thinking "oh I should be working right now" and then waste time talking to friends or on his phone. This meant he would waste a lot of time he'd rather have been working. This introduction to time management is different than the reported cases for communication because it wasn't framed as something someone was doing for themselves or something they would learn about in school - for Jonah it was the lack of skill development that allowed it to transform through coop.

In co-op, Jonah mentions the importance of organizing his time to complete the tasks. He was faced with a longer list of tasks and it was his job to know "how much time ... [he] need[s] on this, how much time [he] need[s] on that". Starting his day by meticulously planning out his time across different tasks became paramount in his co-op days. The level of ownership in this new setting started to show in Jonah's language. Organizing his time was not just something he needed to get better at for himself, it was now central to success in co-op. And as Jonah progressed in his co-op, he found more instances here he had to manage his time of the sake of work completion - and it became more natural than ever before.

When returning to school, Jonah praised the value of time management. Although it wasn't in regard to his specific actions, it did speak to a mindset change. As he described the most needed skill for school, "managing your time wisely and having to complete all those assignments and all the work they have to do". Like in his co-op, time management was a tool to complete his tasks and be on top of his day. It became a holistic guide that framed his actions. And instead of it being something done for the success of a job or to satisfy an employer, the skill was useful to this new, personal challenge. As such, the evolution and transformation across the contexts allowed Jonah to practise time management in his life beyond the contexts he was already familiar with.

\section{2b Organization/ Time Management: Lila}

During school before co-op, Lila talked a lot about the habits she had implemented to organize her time and resources. She specifically mentioned the use of her Surface laptop as a tool, and for her, "everything goes in there" - her calendar, school notes, extracurricular 
commitments, etc. When asked how she realized this worked, she mentioned the conscious trial and error she underwent. Overall, Lila mentioned that she felt her "time management skill was pretty good" so she didn't need to update this skill as much as she implemented it into her regular life. It is important to note the focus of this skill in school. For Lila, organization and time management were used to make her learning simpler and to set her up in a position where she could focus on everything she wanted to. And there was more focus on organizing her many priorities so that she would get to everything. These priorities were not ordered in any particular way.

During co-op, her motivation for organization and time significantly changed. Lila started talking about her time as a commodity, to be optimized and organized to fit the needs of her workplace. She worked in consulting and as she put it: "every hour of your time is billed". This meant there was an element of morality and ethics when organizing her time - "if you're billing time, and you're not getting anything out of it or there's no outputs from that billed time, then you're basically killing someone's budget." As Lila explained, she had to be very honest and productive in the time that she reported because she had a responsibility to her clients. This hyper focus on time as such a valuable asset to have in the work she did, was new. She had always had an inclination towards organization, but she did not grasp the value of the skill and what it meant for her motivations. After her newfound respect for time management, she described her mindset shift: "unless I feel like I'm getting value out of something... I am probably not going to do it". For her, co-op transformed how she saw time value and (as a result) her time management skills.

This transformation was solidified when Lila returned to school. She changed her study patterns to make better use of her time and reminded herself to "stop stressing and sit in the library and do it" when overwhelmed with work. Instead of overscheduling and creating stress for herself, which she fell into the habit of doing before, she started leaping into action. As she put it, "now I don't do thing that I don't want to". Every use of time is tailored to give her value - personal, academic or professional. This school setting took this transformation further because it went from an ethical obligation of honesty for clients to a personal time-value balance. It now exists beyond school and work - a skill she employs in how she conducts herself in any context.

\section{3a Initiative/ Responsibility: Noelle}

In our earlier research [3], many students reported developing their initiative during their co-op placement, but they found it hard to transition this skill back. Students found it hard to have that level of freedom in the school structure. As Taylor put it, "initiative goes further at work than it does in school". Even Jonah found it hard to apply the same level of seeking out work as he had during his coop because of how much work he already was dealing with in school. However, both students were attempting to transition these practises, as opposed to transforming the skills that motivate the practise. With our current conceptual framework, we can analyse how students were able to transform their skills in initiative to be applicable in any situation.

Before co-op, Noelle mentioned being very active in extracurriculars. When asked why, she reported doing it because it was something that she enjoyed. One skill she recalled getting praise for was her ability to confidently "go and ask" questions when she was unsure. Her club experiences also forced her to learn and implement more balance in her life. This is all to say that Noelle recognized a need in her education and pursued a supplement. This is a very personal form of initiative that Noelle took. This initiative was developed/introduced quite informally, done in the form of club involvement.

This was more systemically developed for Noelle in the workplace. Only in co-op did she acknowledge that her initiative is what drove her club involvement. In co-op, Noelle found ways to be more active in her role. She "took an initiative and learn[ed] the whole product" that she worked on, as opposed to just her portion. She realized that she was socially expected to take certain actions that were never explicitly told to her, to have a better learning and work experience: "at the end of the day, what you're doing makes a very small impact for the whole company. But it makes a huge impact for ourselves". There was a personal drive to do better. Not only for the company (even though there is not a huge impact, there was still responsibility) but for a professional environment and development. Later in the interview, Noelle says about action: "it's not just about a job, it's like what you can do to make a change when you leave". Not only did Noelle take initiative by learning more than just her line of code or by engaging with her peers, she even started projects that aided her work. Towards the end of her co-op, she described the projects she had initiated and put into company policy over the four months. She created a company-side wiki site that outlined protocol for documentation within shared code. She noticed that there were unsaid protocols and practises, but she had to learn them over a lot of trial and error. As a response, she created this page that then became a standard that all reviewers within the company had to comply with to share their code. She mentioned how proud she was of this accomplishment and the feedback she received from her supervisor. Another project she worked on and established before coming back to school was a daily blog that chronicled her experiences as an intern. She found that there were a lot of interns in the company who were just as confused by this new environment as she was; and because she was well networked, she found sharing her experiences helped bring people together. When asked about her motivations, she 
said she did these things because she wanted to. She found a gap in the system and took responsibility to find her way of addressing it. This systemic, deeper development of initiative shows how this skill was transformed into being more intentional and impactful than it was in school.

Upon returning to school, Noelle continued her club involvement and found more ways to fulfill herself. The biggest change we noticed was her mindset. She started looking at her new passion projects and previous club experiences as personal growth. As Noelle said, "working directly in the industry [helped her] focus [her] goals more". These actions became more determined and oriented around her success. Noelle even recognized that with her busy schedule and the nature of her program, there were fewer outlets for her to be involved her personal development; and so, she started pursuing these efforts outside of school. She mentioned starting an online blog chronicling tips and tricks that helped her succeed in courses, her journey towards a healthy lifestyle (as a student), cooking, etc. She wanted to find a way to integrate this into the school and until then, she wanted to continue "creating these resources". This venture into personal passions exemplifies Noelle's initiative transformation. Originally this skill was unintentional and casual; in co-op it was used to improve the work culture. And when she returned to school, this skill became a guiding force for her personal and professional development. It was not limited by context or audience. In essence, this skill was quite drastically transformed.

\section{3b Initiative/ Responsibility: Idris}

Before co-op, Idris mentioned a little bit about him having "an external passion [and] starting your own individual projects". He did not necessarily care for clubs as much as doing things to expand on his knowledge and passions. He found opportunities to learn new programming languages, improving his circuit board building and even working on a robot. These experiences were all internally motivated, much like most of his schoolwork. And all of these experiences he mentioned would be helpful in more than just the following co-op he was in. This awareness of the transient nature of these technical skills shows the intentionality behind his actions. Also, Idris recognizing the need to take action to fulfil his interests shows a grasp on initiative as a skill. Although not developed, it is something he has seen the use of in the school culture.

During co-op, Idris showed a lot of change. When describing his overall experience, he had a lot of ownership and confidence. Working in the security industry, Idris mentioned how his responsibility was no more than just something that would affect him; his "irresponsibility could affect other people... [there's] a lot more incentive to be more responsible". For him, his actions had more impact and value. This is not to say that there was no more individual impact - his misstep would have professional and monetary consequences. This shift towards corporate responsibility was something he highlighted as a huge change for him. This also "did drive [him] to do better", according to him. He had to find more optimized ways to manage his time, communicate with his co-workers, learn new material, etc. He also learned how to ask questions when he was confused. When he was in school, Idris mentioned feeling "apprehensive to ask for help" for fear of being ridiculed. But in co-op he was trained to take that initiative and he internalized that to create a better work environment for himself. And this assertiveness in this new setting made it so that he was comfortable learning about new products and talking with different teams to learn more about the company's practises. He specifically mentioned how initiative allowed him to "gain a more holistic sense of the product itself" and this understanding allowed him to do his job with more efficiency and improve his learning, on the whole.

As we mentioned, confidence was a huge development for Idris. The language he used to describe his experiences and behaviour through co-op had more ownership. Idris was unique in the fact that he had the longest co-op placement, and his placement took him nearly across the country. He had to overcome a level of personal and professional culture shock. And through these experiences, he learned about the benefit of skill transformation. He found that these skills he picked up, motivated him to take the next step in forwarding his career - whatever that meant. He was confident in his ability to thrive in whatever culture he needs to because he felt that it was always in his hands to improve and do better. This personal responsibility was seen in school, to some extent; however, through co-op Idris felt more confident and it was expanded to more specific career alignment.

When returning to school, Idris brought this confidence in full strength. Idris mentioned that he was finding it hard to find as many clear, open opportunities to take charge in the conformed structure of school, but he was excited to express himself in the courses and projects he did do. These opportunities "really pushed [him] forward and made [him] realize that there's a lot more to it than just sitting in a classroom doing worksheets". The initiative he had developed in co-op - taking action, exploiting every opportunity for maximum learning, using ambiguous prompts to define meaning for self - was transformed for more than one use. All of these characteristics he could now apply in the classroom. And the responsibility to self and others was also seen in the way he would interact with teammates. He mentioned feeling that same responsibility even before co-op, but after working, there was a newfound respect and empathy for others. Be it the school system, teammates, classmates; he found a more holistic view on the responsibility he had to others. And his experience back 
at school took the originally personal and then ethical responsibility based in consequences towards a more positive, human trait. This very clearly shows how all 3 contexts allowed Idris to transform his initiative skills to be more confident, beyond known contexts.

\section{SUMMARY AND CONCLUSION}

In this paper, we analysed the transformation of employability skills through co-op. Using Mezirow's Transformative Learning Theory as a foundation, we proposed a framework (fig. 1) that highlights the impact and importance of three contexts: school before entering co-op, the co-op work term, and returning to school after co-op. Each of these experiences lead to the next stage and together, transforms a student's skill. With accounts from the four participants, we explored the transformation of three main skills: communication, time management/ organization and initiative/ responsibility. We also explored how different students will transform in different ways, even within this framework.

Lila's communication was transformed to be used to understand and solve problems. Noelle's communication was transformed such that she can now rely on her skills and is not limited by her past experiences. Idris's communication transformed into a personal value that he learned to apply in any context. Jonah's organization was transformed to allow more ownership and application to personal growth. Lila's time management became time value, which now motivated her actions, as opposed to the opposite. Noelle's initiative was transformed into a guiding force that motivated her to seek out personal projects and supplement resources where they were lacking. Finally, Idris's initiative was transformed into confidence and a drive to achieve excellence when faced with ambiguous opportunities.

In all of these cases, there is a transformation of each skill. Even if these skills are not transformed in the same way, they all rely on those same three experiences to compound and build from each other. For example, without the experience of communication as a tool that co-op gave Lila, she could not have been able to see communication as a way to process and deal with problems that may arise, no matter the context. And if she had not developed an understanding of professionalism in school even before coop, she would not have been able to expand her communication to be used as a tool or valued it in the school setting after returning. As exemplified, each of these experiences feed into each other and help complete the transformation.

Furthermore, this framework proposes a way for us to see transformative learning through skills. Co-op and other work-based programs use skill growth as a major metric to gauge and track learning. Unless we have a way to recognize the transformational aspect of skills and experiences, we risk not capturing a learner's growth. This was evident in the ability for students to transform skills such as initiative for school settings but not transitioning it. We can see that this framework gives educators a great way of capturing the nuances of skills and co-op experiences. By no means is this the only framework that exists - but it is a start to explore the intersection of transformative learning and skill development.

\subsection{Limitations and Future Work}

The initial set of interviews followed a context change from school to co-op. And so, some students had started the reflection process to adapt to their workplace. When discussing skills that they used in school, they had already started comparing it to the workplace (as was described by Noelle when speaking about communication). This did not compromise our research project, especially because the phenomenological methodology allowed us to reduce these instances of reflection to a handful. It is important to be aware, however, that this did need to be kept in mind when analyzing. In the future, it could be interesting to see how having 3 interviews per participant could alter responses.

Furthermore, we initially explored teamwork as an independent skill that could be measured and tracked. Yet, throughout the analysis, we found that students used skills such as organization and communication to boost their performance in team settings. This is not to say that teamwork is not a skill that has the capacity to transform; it just means that in the scope of our questioning and analysis, we could not extract enough independent testimony to report on its transformation. As a result, we used other skills to discuss team performance and how that has been transformed for students. In addition, we do keep in mind that there should be more of a focus on teamwork skills in any future iterations of this work.

In this paper, we focused on co-op programs and how they facilitate the transformation of skills through context. This is not to say that this is the only context change available to students or that co-op programs are the sole avenue for skills transformation. In actuality, there are many WIL programs, volunteer- and community-based programs and extracurricular experiences that offer similar results. Work done by Reedy, et. al. shows the skill development through a non-placement WIL program [17]; they highlighted a model of education that encouraged employability skill development. Work with similar subject matter, under the lens of transformation, would be helpful to explore in the future.

This paper represents diversity in gender and program. This addressed a concern mentioned in the previous paper regarding number of participants. Our selected sample size is in accordance with the nature of qualitative methods. As 
discussed by Case and Light, the goal of qualitative data is not statistical generalization but to gain "situational perspectives" [18]. As such, this project aimed to highlight the experiences of the participants in the group and the number of participants achieved representative sampling.

\section{ACKNOWLEDGEMENTS}

We would like to thank the participants for dedicating their time and sharing their experience for this project. We would also like to thank the Lassonde School of Engineering and York University for providing the setting at which to do this research.

The data collection for this paper is in compliance with the ethics guidelines set forth by York University per certificate number e2018 - 178 .

\section{REFERENCES}

[1] Cooperative Education and Work-integrated Learning (CEWIL) Canada. "About Us". Internet:

https://www.cewilcanada.ca/about-us.html [Jan. 10, 2019]

[2] Geraldine Van Gyn, James Cutt, Makrk Loken, and Frances Ricks. "Investigating the Educational Benefits of Cooperative Education: A Longitudinal Study". Journal of Cooperative Education, vol. 32(2) n2 pp. 70-85, 1997.

[3] Andrew Kitchenham. "The Evolution of John Mezirow's Transformative Learning Theory". Journal of Transformative Education, vol. 6(2), pp. 104-123, 2008.

[4] Haaniyah Ali and Jeffrey Harris. "Transferable Skills: From Work to School". Proc. CEEA Annual Conference, (Ottawa, Canada, 8-12 Jun. 2019), 8pp., 2019. Available as of March 5, 2021 from

https://ojs.library.queensu.ca/index.php/PCEEA/article/view/137 $\underline{91}$

[5] Nashwan Younis "Cooperative Education Impact on Enhancing Mechanical Engineering Curriculum" in Proc. ASEE Annual Conference \& Exposition, (San Antonio, Texas, 10-13 Jun, 2012), 19 pp., 2012. Available as of March 5, 2021 from https://peer.asee.org/cooperative-education-impact-onenhancing-mechanical-engineering-curriculum

[6] Aaron Simon Blicblau, Tracey Lousie Nelson and Kurosh Dini. "The role of work placement in engineering students' academic performance". Asia-Pacific Journal of Cooperative Education, vol. 17(1), pp. 31-43, 2016.

[7] N.L. Driffield, C.S. Foster and H.E. Higson. "Placement and degree performance: Do placements lead to better marks, or do better students choose placement?" in Proc. ASET Annual Conference, Mark Hart, et. al (ed.) (Leeds, England; 6-8 Sept, 2011), 24 pp., 2011. Available as of March 5, 2021 from http://publications.aston.ac.uk/18824/1/Placements_and_degre e_performance.pdf
[8] John Duignan. "Undergraduate work placement and academic performance: Failing by doing". Proc. Research and Development in Higher Education: Quality Conversations (HERDSA), vol. 25 pp. 214- 221, 2002. Available as of March 5, 2021 from

https://www.researchgate.net/publication/241018279_Undergrad uate_work_placement_and_academic_performance_Failing_by_ doing

[9] Giselle Rampersad and Vlatka Zitvotic-Kukolj, "Workintegrated learning in science, technology, engineering and mathematics: Drivers of innovation for students". International Journal of Work-Integrated Learning, 19(2), 193-204, 2018.

[10] Mahmoud Haddara and Heather Skanes. "A reflection on cooperative education: from experience to experiential learning". Asia-Pacific Journal of Co-operative Education, vol. 8(1), pp. 67-76, June 18, 2007.

[11] Stephen Johnston and Helen McGregor, "Recognizing and Supporting a Scholarship of Practice: Soft Skills are Hard!" Asia-Pacific Journal of Cooperative Education, vol. 6(1), pp. 16, 2005.

[12] Jenna Gillett-Swan and Deanna Grant-Smith. "A Framework for managing the impacts of work-integrated learning on student quality of life". International Journal of Work-Integrated Learning, vol. 19(2), pp. 129-140, 2018.

[13] Haaniyah Ali and Jeffery Harris. "Development of Employability Skill in Engineering Disciplines through Co-op". Proc. ASEE Virtual Conference, (20-25 Jun. 2020), 22 pp., 2020. Available as of March 5, 2021 from https://www.asee.org/public/conferences/172/papers/30184/view

[14] Norah McRae. "Exploring conditions for transformative learning in work-integrated education". Asia- Pacific Journal of Cooperative Education Special Issue, vol. 16(2), pp. 137-144, 2015.

[15] Céline Buchs and Fabrizio Butera. "Chapter 11: Cooperative Learning and Social Skills Development" in Collaborative Learning: Developments in Research and Practice. Robert Gilles (ed). New York: Nova Science, 2015, $362 \mathrm{pp}$. Available as of March 5, 2021 from https://www.researchgate.net/publication/272197928_Cooperati ve_learning_and_social_skills_development

[16] Jenny Reilly and Tatiana Teslenko. "The role of cooperative education in ensuring students' success when transitioning from classroom to industry". Proc. IEEE International Professional Communication Conference, pp. 1-6, 2015. Available as of March 5, 2021 from https://ieeexplore.ieee.org/document/7020361

[17] Alison K. Reedy, María Lucía Guerrero Farías, Luis H. Reyes, Diego Pradilla. "Improving employability skills through non-placement work-integrated learning in chemical and food engineering: A case study". Education for Chemical Engineers, vol. 33, pp. 91-101, 2020.

[18] Jennifer M. Case, Gregory Light. "Emerging Methodologies in Engineering Education Research". Journal of Engineering Education, vol. 100(1), pp. 186-210, 2011. 